\title{
INTERNAL CONSISTENCY, RESPONSIVENESS AND MINIMAL DETECTABLE CHANGE OF THE TECO IN THE BACHELOR'S DEGREE COURSE IN PEDIATRIC NURSING AT THE "SAPIENZA" UNIVERSITY OF ROME: A CROSS SECTIONAL STUDY
}

\author{
Giovanni Galeoto ${ }^{1}$, Giuliana D'Elpidio ${ }^{2}$, Rosaria Alvaro ${ }^{3}$, Anna Maria Zicari ${ }^{4}$, Donatella Valente ${ }^{1}$ \\ and Marianna Riccio ${ }^{5}$ \\ ${ }^{1}$ Department of Human Neurosciences, Sapienza University of Rome, Rome, Italy \\ ${ }^{2}$ Bambino Gesù Pediatric Hospital- IRCCS, Piazza Sant'Onofrio 4, Rome, Italy \\ ${ }^{3}$ Full-Professor of Tor Vergata University of Rome, Rome, Italy \\ ${ }^{4}$ Department of Pediatric, Sapienza University of Rome, Rome, Italy \\ ${ }^{5}$ Sapienza University of Rome, Piazzale Aldo Moro 5, Rome, Italy
}

\begin{abstract}
The Italian Disciplinary section of Test of Competences (TECO-D) project is an important longitudinal study used to analyze learning outcomes of ungraded students and to measure quality of the educational process. The aim of the present study was to evaluate the psychometric properties of the TECO-D in students enrolled in the Bachelor's Degree in Pediatric Nursing at "Sapienza" University of Rome. The other aim was to evaluate if TECO-D is able to assess the changes in skills between students of I and III year of the university course and to calculate the minimal detectable change. The sample was composed by 35 pediatric nursing students and was recruited in October 2019. The test was administered using a digital platform with multiple choice questions (MCQs). The reliability, as internal consistency, was excellent $(\alpha=0.938)$. The responsiveness evaluated by t-test for independent samples, the Standard Error of Measurement (SEM) and Minimal Detectable Change (MDC) was supported by significant differences between two cohorts of pediatric nursing students, and adequate TECO-D is a reliable instrument for assessing the skills of pediatric nursing student evaluating the achievement of university goals and improving the quality of the training provided by the university.
\end{abstract}

\section{KEYWORDS}

TECO, Progress Test, Pediatric Nursing, Students

\section{INTRODUCTION}

The longitudinal progress testing assessment developed in the early 1970s at the University of Missouri-Kansas City School of Medicine and at the University of Limburg in Maastricht. It has since become increasingly popular internationally due to obvious advantages. Progress test periodically measure entire body of student's knowledge during their learning process. Thus, it is useful for the new medical schools to establish a comparison in terms of achievement with more prestigious medical schools (Schuwirtf, 2012) (Verhoeven, 2002). Progress test can be also used to identify both strengths and weaknesses in student's knowledge and as a self-assessment tool that give cross-sectional measure of individual's performance that each student can compared with their peers. For the administration usually multiple choice questions (MCQs), that are randomly drawn from a database (Verhoeven, 2002) (Wrigley, 2012).

Based on this principle, (Test Of Competence) TECO project coordinated by National Agency for the Evaluation of Universities and Research Institutes (ANVUR) was established in Italy in 2012. The agency avails of academic representatives who compose in working groups (WG) associated by the Executive Council. The TECO project evaluates and monitors the skills of undergraduate students and results of training course. 
The aim of testing is to measure and to improve the quality of the educational process by encouraging mechanisms within the academic self-assessment world. Therefore TECO, promotes student centered teaching associated by the analysis of learning outcomes, as recommend by the recent European guidelines (Standards and Guidelines for Quality Assurance, 2015) of the European Area of Higher Education (EHEA). TECO project proposes both Trasversal section (TECO-T) and Disciplinar section (TECO-D) (ANVUR, 2020) (ESG, 2015). TECO-D analyses specific training contents of the course and students are examined with digital platform managed by Consorzio INteruniversitario pEr il Calcolo Automatico dell'Italia (CINECA) in classrooms on the university campus. The time testing is established by the ANVUR in collaboration with the CINECA (usually September - December).

The Bachelor's Degree in Pediatric Nursing provides didactic courses and experiences of clinical practice intended for the training of health professionals expertise in the care of healthy and sick children and family/caregivers. The studies objectives allow future pediatric nurses to develop specific care and relation skills in relation to the specific stage of childhood. The medical pediatric specialty is crucial because a pediatric patient has physical, physiological and psychological features quite different from the characteristics of an adult patient. For this reason, health professional expert and specifically trained are necessary to adequately satisfy the needs regarding the nursing of pediatric patient. Therefore, the importance of careful assessment of the skills of future pediatric nurses to ensure quality and safety in care is evident and key. The dawn of pediatric nursing history dates back to 1852-1854 when the doctor Charles West found one of the first pediatric hospitals in the world. He highlighted the need of nurses with a firm grip in the care of sick child. Italian pediatric nursing has one's origins in historical health figure named "vigilatrice di infanzia", officially recognized in 1940. During the mid-twentieth century this first health pediatric figure had an important professional role. The position developed parallel to that of the generalist nurse acquiring greater autonomy and responsibility. It was only in 1997 the profession of pediatric nurse has been was finally regulated by Ministerial Decree n. 70 (FNOPI) (Costamagna, 2010).

For the academic year 2019 - 2020 the test was adopted in "Sapienza" University of Rome for the Bachelor's Degree courses in Pediatric Nursing. This study aimed to evaluate the reliability, as internal consistency and the responsiveness, in term of significant difference in skills between pediatric nursing students of First and Third years in "Sapienza" University, of the TECO-D for Bachelor's Degree courses in Pediatric Nursing (ANVUR, 2020).

\section{MATERIALS AND METHODS}

\subsection{Population and Procedures}

The data were gathered from 35 students enrolled in the Bachelor's Degree in Pediatric Nursing at "Sapienza" University of Rome: 15 of First year of course and 20 of Third year of course. The students were approached in October 2019 and were invited and informed about the modalities of test by email. Participation was voluntary. The individual results of tests were communicated to each participating students by certificate available from February 2020 and the outcomes did not affect the evaluation in progress or the final assessment. The accumulated data were transmitted to the responsible coordinators of the study courses involved and to the university board (ANVUR, 2020).

\subsection{Instruments}

TECO-D for pediatric nursing students was created by specific working group that had reworked 70 questions by database containing 250 questions. Multiple choice questions (MCQs), divided into thirteen care macro areas (Table 1), with only one correct answer composed the TECO-D. The test was administered using a digital platform managed by CINECA (Figure 1 shows the graphic interface) in a university classroom equipped with computers within 90 minutes (ANVUR, 2020). 
The process of creation/administration of the test of this institutional platform, in general, requires the participation of three persons with three different roles. There is a different reserved access area for each of the three roles. The University Contact creates and prepares the exam session; the Classroom Tutor opens and closes the administration of the test; the student compiles and sends the test data. The registration on the website Universitaly (a platform of Ministry of education, university and research) by students is an essential requirement in order to do the test. There are present "Summery" pages in each phase that give indications on missing answers and the "Delivery" button that concludes the current phase. Before the conclusion, the student receives a confirmation message that warns him of the impossibility of being able to re-enter the current phase (Galeoto, 2019) (Paterniani, 2019).

Table 1. Macro areas of TECO-D

\begin{tabular}{|l|l|l|}
\hline Number of macro areas & Learning & Number questions \\
\hline 1 & Transversal care skills & 12 \\
\hline 2 & Vital critically & 8 \\
\hline 3 & Cardio-respiratory & 6 \\
\hline 4 & Hematology & 6 \\
\hline 5 & Metabolic & 2 \\
\hline 6 & Gastro-intestinal & 4 \\
\hline 7 & Renal & 3 \\
\hline 8 & Neurological Neuropsichiatric & 5 \\
\hline 9 & Surgical & 5 \\
\hline 10 & Health prevention & 5 \\
\hline 11 & Nursing care safety & 8 \\
\hline 12 & Organization & 3 \\
\hline 13 & Ethical responsibility & 4 \\
\hline
\end{tabular}

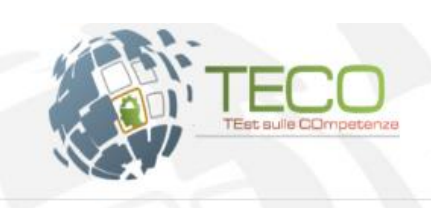

Test sulle Compentenze generaliste, TECO

Area iservata per lacoesss al lest di verica sulfe competenze genteralste, TECO.

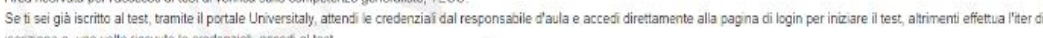
iscrizone e, una volla ricevite le credenzial, accosi al lest
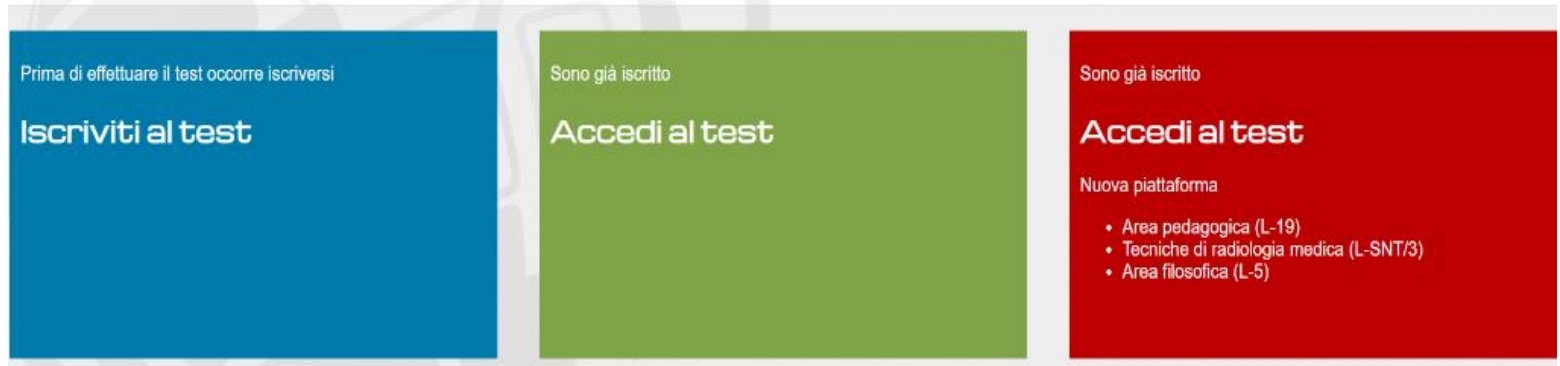

Figure 1. CINECA platform (CINECA, 2020) 


\subsection{Data Collection and Data Analyses}

The data of TECO-D of the two years of course was collected in October 2019. Ethical approval was obtained. Participants were fully informed about the study's aims and gave their consent. Instruments were all anonymous, and participants were assured about data confidentiality.

Analyses were performed using SPSS 23.0 (IBM Corp., Armonk, NY, USA). Descriptive analyses were conducted: continuous and categorical variables were reported as means $( \pm \mathrm{SD})$ and frequencies $(\%)$. The reliability, as internal consistency, of the TECO-D was tested by Cronbach's alpha coefficient, values greater than 0.70 were adequate.

To evaluate the responsiveness, defined as "the ability of an instrument to detect change over time in the construct to be measured" (Mokking, 2010) t-test for independent samples, the Standard Error of Measurement (SEM) and Minimal Detectable Change (MDC) were carried out.

Specifically, in the t-test for independent samples, we compared the TECO-D scores reported in the first and third year by pediatric nursing students. Significant differences indicate that the instrument was able to measure the difference in skills between the two cohorts of student.

The Standard Error of Measurement (SEM), an indication of the absolute reliability, was calculated through the error term from the 2-way model (MSE) of the repeated measures ANOVA. The SEM value lower than Standard Deviation/2 identifies higher reliability of the measure.

The Minimal Detectable Change (MDC), the minimal amount of change that can be interpreted as a real change in acquired competencies for a student during the years, was computed using SEM according to the following formula, $\mathrm{MDC}=\mathrm{SEMx} 1.96 \times \sqrt{ } 2$.

\section{RESULTS}

\subsection{Population}

The sample was composed by 35 students of the Bachelor's Degree in Pediatric Nursing at "Sapienza" University of Rome: 15 of First year of course and 20 of Third year of course. The average age of the participants was 21 years and the predominant gender was female.

\subsection{Internal Consistency}

The score of internal consistency for the TECO-D was excellent $(\alpha=938)$.

Table 2

\begin{tabular}{|l|r|r|r|r|}
\hline Area & $\begin{array}{c}\text { Scale Mean if } \\
\text { Item Deleted }\end{array}$ & $\begin{array}{c}\text { Scale Variance if Item } \\
\text { Deleted }\end{array}$ & $\begin{array}{c}\text { Corrected Item-Total } \\
\text { Correlation }\end{array}$ & $\begin{array}{c}\text { Cronbach's Alpha } \\
\text { if Item Deleted }\end{array}$ \\
\hline 1 & 21.11 & 192.752 & 0.712 & 0.937 \\
\hline 2 & 23.23 & 200.829 & 0.637 & 0.939 \\
\hline 3 & 25.23 & 213.593 & 0.701 & 0.933 \\
\hline 4 & 25.34 & 210.820 & 0.879 & 0.928 \\
\hline 5 & 26.20 & 227.341 & 0.772 & 0.934 \\
\hline 6 & 25.66 & 216.585 & 0.813 & 0.931 \\
\hline 7 & 25.51 & 213.963 & 0.832 & 0.930 \\
\hline 8 & 25.74 & 225.726 & 0.710 & 0.935 \\
\hline 9 & 25.46 & 213.138 & 0.812 & 0.930 \\
\hline
\end{tabular}




\begin{tabular}{|l|r|r|r|r|}
\hline 10 & 24.91 & 219.257 & 0.631 & 0.935 \\
\hline 11 & 24.26 & 190.255 & 0.870 & 0.928 \\
\hline 12 & 26.14 & 227.950 & 0.683 & 0.935 \\
\hline 13 & 25.20 & 212.400 & 0.752 & 0.932 \\
\hline
\end{tabular}

\subsection{Responsiveness}

The evaluation of the responsiveness evaluated by t-test for independent samples showed statistically significant data in the comparison of the results of the two cohorts of pediatric nursing students.

The SEM and MDC and responsiveness are reported in Table 3.

Table 3. Responsiveness and Minimal Detectable Change

\begin{tabular}{|r|r|r|r|r|r|r|}
\hline Area & $\begin{array}{c}\text { Administration } \\
\text { 2019 in First year } \\
(\text { means } \pm \text { SD) }\end{array}$ & $\begin{array}{c}\text { Administration } \\
\text { 2019 in Third year } \\
(\text { means } \pm \text { SD) }\end{array}$ & $\begin{array}{c}\text { Mean } \\
\text { Difference }\end{array}$ & SEM & $p$ & MDC \\
\hline 1 & $3.80 \pm 2.18$ & $7.45 \pm 1.2$ & -3.65 & 0.59 & 0.00 & 1.63 \\
\hline 2 & $2.07 \pm 1.53$ & $5.05 \pm 1.99$ & -2.98 & 0.61 & 0.00 & 1.71 \\
\hline 3 & $0.47 \pm 0.64$ & $2.75 \pm 1.33$ & -2.28 & 0.37 & 0.00 & 1.03 \\
\hline 4 & $0.40 \pm 0.83$ & $2.60 \pm 0.88$ & -2.20 & 0.29 & 0.00 & 0.81 \\
\hline 5 & $0.00 \pm 0.00$ & $1.40 \pm 0.68$ & -1.40 & 0.18 & 0.00 & 0.49 \\
\hline 6 & $0.33 \pm 0.72$ & $2.10 \pm 1.02$ & -1.77 & 0.31 & 0.00 & 0.86 \\
\hline 7 & $0.40 \pm 0.82$ & $2.30 \pm 1.03$ & -1.90 & 0.33 & 0.00 & 0.90 \\
\hline 8 & $0.47 \pm 0.74$ & $1.85 \pm 0.75$ & -1.38 & 0.25 & 0.00 & 0.70 \\
\hline 9 & $0.40 \pm 0.83$ & $2.40 \pm 1.10$ & -2.00 & 0.34 & 0.00 & 0.94 \\
\hline 10 & $0.93 \pm 1.28$ & $2.95 \pm 0.83$ & -2.02 & 0.36 & 0.00 & 0.99 \\
\hline 11 & $4.10 \pm 1.4$ & $0.27 \pm 0.46$ & -3.17 & 0.53 & 0.00 & 1.48 \\
\hline 12 & $1.30 \pm 0.98$ & $0.60 \pm 0.99$ & -1.03 & 0.27 & 0.00 & 0.76 \\
\hline 13 & $0.60 \pm 0.99$ & $2.70 \pm 1.22$ & -2.10 & 0.38 & 0.00 & 1.06 \\
\hline 13 & $11.07 \pm 7.57$ & $38.96 \pm 7.16$ & -27.88 & 2.51 & 0.00 & 6.95 \\
\hline
\end{tabular}

$* \mathrm{p}<0.05 * \mathrm{SD}=$ Standard Deviation $* \mathrm{SEM}=$ Standard Error of Measurement $* \mathrm{MDC}=$ Minimal Detectable Change

\section{DISCUSSION}

The study was conducted by a research group from the "Sapienza" University of Rome and from "Rehabilitation \& Outcome Measure Assessment" (R.O.M.A.) association (Berardi, 2019) (Galeoto, 2020) (Ioncoli, 2020) (Miniera, 2020) (Panuccio, 2020).

The TECO project is an instrument to evaluate and monitor the skills of undergraduate students and results of training course. It proposes two sections: Trasversal section (TECO-T) and Disciplinar section (TECO-D). This study aimed to evaluate the reliability, as internal consistency and the responsiveness, in term of significant difference in skills between pediatric nursing students of First and Third years in "Sapienza" University, of the TECO-D for Bachelor's Degree courses in Pediatric Nursing.

The psychometric properties of TECO-D for Bachelor's Degree in Pediatric Nursing had a very positive evaluation: we defined an excellent internal consistency, which means that the all items of the TECO-D were strongly interrelated with each other and that the TECO-D IS a reliable instrument for assessing the skills of pediatric nursing student.

The analysis of responsiveness and the evaluation of MDC highlighted an improvement statistically significant of TECO- D's results between First and Third years. So we can say that the TECO-D is an instrument sensitive to the change of competences between First and Third years, although the two cohorts of this study were not represented by the same sample. 


\subsection{Limitation of the Study}

This study present several limitations. First we collected data using a convenience sample. Second, it was not possible to assess the change in skills of the same sample of students over time. Third, the responsiveness was analyzed comparing two different cohort (First and Third years) using TECO-D results from the same year of administration (2019). Fourth, a reduced size sample was used to perform analysis. Further studies with larger samples are needed.

\section{CONCLUSION}

The TECO-D can be considered a reliable tool for assessing the skills of students of the Bachelor's Degree in Pediatric Nursing. The TECO-D test is able to catch statistically significant changes in the skills of pediatric nursing students and the minimal detectable change value necessary for the TECO-D score change to be significant year after year. TECO-D can be useful to achievement of university goals and to improve the quality of the training provided by the university. Therefore, an increasingly widespread and consolidated use of TECO-D can be hoped for in order to intervene in a timely manner if critical issues arise in the learning process. This is a particularly important intervention for the training of those who will carry out a health profession in the future.

\section{CONFLICT OF INTEREST}

The authors declare that they have no conflict of interest.

\section{REFERENCES}

ANVUR homepage, https://www.anvur.it/attivita/ava/teco-test-sulle-competenze/ last access 2020/07/10 https://enqa.eu/wp-content/uploads/2015/11/ESG_2015.pdf , last access 2020/07/10

ANVUR homepage https://www.anvur.it/attivita/ava/teco-test-sulle-competenze/rilevazioni-teco/ last access 2020/07/10

ANVUR homepage, https://www.anvur.it/attivita/ava/teco-test-sulle-competenze/rilevazioni-teco/la-rilevazione-teco2019/, last access 2020/07/10

ANVUR https://www.anvur.it/wp-content/uploads/2019/08/TECO-D-Infermieristica-Pediatrica.pdf, last access 2020/07/15

Berardi A. et al, 2019. Internal consistency and validity of the Jebsen-Taylor hand function test in an Italian population with hemiparesis. NeuroRehabilitation, vol. 45, no. 3, pp 331-339.

CINECA https://verificheonline.cineca.it/teco/login_studente.html, last access 2021/01/27

Costamagna G., 2010. Lo sviluppo dell'Infermieristica Pediatrica in Italia. Giornale Italiano di Scienze Infermieristiche Pediatriche, vol. 2, no. 4, pp 116-118.

FNOPI https://www.fnopi.it/aree-tematiche/infermieristica-pediatrica/ , last access 2020/07/28

Galeoto G. et al, 2019. J. The use of a dedicated platform to evaluate health-professions university courses. in Advances in Intelligent Systems and Computing. pp 275-284

Galeoto G. et al, 2020. Levels of Cognitive Functioning Assessment Scale: Italian cross-cultural adaptation and validation. Annali di igiene: medicina preventive e di comunità, vol. 21, no. 1, pp 16-26.

Ioncoli M. et al, 2020. Crosscultural Validation of the Community Integration Questionnaire-Revised in an Italian Population. Occupational Therapy International, vol. 2020, 9816541.

Mokkink L. B. et al, 2010. International consensus on taxonomy, terminology, and definitions of measurement properties: Results of the COSMIN study. Journal of Clinical Epidemiology, vol. 63, no. 7, pp 737-745.alfabet

Miniera f. et al, Measuring Environmental Barriers: Validation and Cultural Adaptation of the Italian Version of the Craig Hospital Inventory of Environmental Factors (CHIEF) Scale. Occupation Therapy Health Care, vol. 34, no. 4, pp 373-385. 
Paterniani A. et al, 2019. Electronic Test of Competence Administration: Qualitative Evaluation of Students' Satisfaction on Telematic Platform a Cross Sectional Study. Advances in Intelligent Systems and Computing. Spain, pp 47-54.

Panuccio F. et al, 2020. Development of the Pregnancy and Motherhood Evaluation Questionnaire (PMEQ) for evaluating and measuring the impact of physical disability on pregnancy and the management of motherhood: a pilot study. Disability Rehabilitation, vol. 42, no.4, pp 1-7.

Schuwirtf L., Van der Vleuten C, 2012. The use of progress testing. Prospectives on Medical Education, vol. 1, n. 1, pp. 24-30.

Verhoeven BH. et al, 2002. Growth in medical knowledge. Medical Eduction, vol. 36, n. 7, pp 11-7.

Wrigley W. et al, 2012. A systemic framework for the progress test: Strengths, constraints and issues: AMEE Guide. Medical Teacher, vol. 71, no. 34, pp 683-697. 